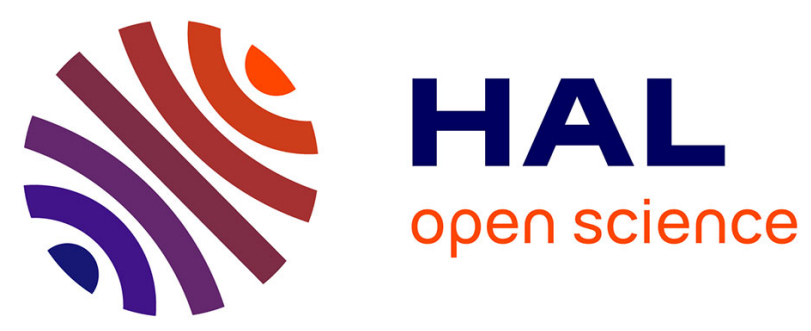

\title{
Earthworm cast production as a new behavioural biomarker for toxicity testing.
}

Yvan Capowiez, Nils Dittbrenner, Magali Rault-Léonardon, Rita Triebskorn, Mickael Hedde, Christophe Mazzia

\section{> To cite this version:}

Yvan Capowiez, Nils Dittbrenner, Magali Rault-Léonardon, Rita Triebskorn, Mickael Hedde, et al.. Earthworm cast production as a new behavioural biomarker for toxicity testing.. Environmental Pollution, 2010, 158 (2), pp.388-393. 10.1016/j.envpol.2009.09.003 . hal-02666588

\section{HAL Id: hal-02666588 \\ https://hal.inrae.fr/hal-02666588}

Submitted on 31 May 2020

HAL is a multi-disciplinary open access archive for the deposit and dissemination of scientific research documents, whether they are published or not. The documents may come from teaching and research institutions in France or abroad, or from public or private research centers.
L'archive ouverte pluridisciplinaire HAL, est destinée au dépôt et à la diffusion de documents scientifiques de niveau recherche, publiés ou non, émanant des établissements d'enseignement et de recherche français ou étrangers, des laboratoires publics ou privés. 


\title{
Earthworm cast production as a new behavioural biomarker for toxicity testing
}

\author{
Yvan Capowiez $^{\mathrm{a}, *}$, Nils Dittbrenner ${ }^{\mathrm{a}, \mathrm{b}}$, Magali Rault ${ }^{\mathrm{c}}$, Rita Triebskorn ${ }^{\mathrm{b}}$, \\ Mickaël Hedde ${ }^{\mathrm{d}}$, Christophe Mazzia ${ }^{\mathrm{c}}$ \\ a INRA, UR1115 “Plantes et Systèmes Horticoles”, Domaine Saint Paul, 84914 Avignon Cedex 09, France \\ ${ }^{\mathrm{b}}$ Animal Physiological Ecology, University of Tübingen, Konrad-Adenauer-Str. 20, D-72072 Tübingen, Germany \\ ' UAPV, UMR406 “Abeilles et Environnement", Domaine Saint Paul, 84914 Avignon Cedex 09, France \\ d INRA, UR251 “PESSAC”, RD10, 78026 Versailles Cedex, France \\ Cast production of Lumbricus terrestris is affected by pesticides under laboratory conditions.
}

\section{A R T I C L E I N F O}

\section{Article history:}

Received 6 May 2009

Received in revised form

31 August 2009

Accepted 2 September 2009

\section{Keywords:}

Egestion rate

Imidacloprid

Carbamates

Organophosphorous insecticides

Lumbricus terrestris

\begin{abstract}
A B S T R A C T
There is currently a lack of ecotoxicity tests adapted to earthworm species of higher ecological relevance and whose endpoints could be directly related to their ecological role in the soil. We propose a new and relatively simple ecotoxicity test based on the estimation of cast production (CP) by Lumbricus terrestris under laboratory conditions. CP was found to be linearly correlated to earthworm biomass and to be greatly influenced by soil water content. Azinphos-methyl had no effect on $\mathrm{CP}$ at all the concentrations tested. Significant decreases were observed at the normal application rate for other pesticides with (imidacloprid, carbaryl, methomyl) or without (ethyl-parathion and chlorpyrifos-ethyl) a clear concentration-effect response. For the highest concentration tested, reduction in CP varied between 35 and $67 \%$. $\mathrm{CP}$ is straightforward and rapidly measured and ecologically meaningful. We thus believe it to be of great use as an endpoint in ecotoxicity testing.
\end{abstract}

(c) 2009 Elsevier Ltd. All rights reserved.

\section{Introduction}

Earthworms, as ecosystem engineers (Jones et al., 1994) have a great influence on many physical (transfer properties), chemical (biogeochemical cycles) and biological (interactions with other components of the soil ecosystem) processes that occur in the soil (McCoy et al., 1994; Görres et al., 2001). They are therefore important terrestrial model organisms requiring toxicity testing. To date, a number of normalized tests using Eisenia fetida and focusing on mortality, reproduction and behaviour (avoidance) are available. Changes in behaviour are promising targets for ecotoxicological studies because the results can be linked to effects at the ecosystem level (Little, 1990; Doving, 1991; Scherrer, 1992). In the case of earthworms, changes in behaviour such as modified or reduced burrowing activity are crucial factors because these could have drastic effects on soil functioning (Capowiez et al., 2006). Although significant modifications to earthworm burrow systems due to the presence of pollutants have been sometimes observed (Eijsackers et al., 2001; Capowiez et al., 2003), it is difficult to study earthworm behaviour because these animals are concealed by the soil in which they live. Previous attempts to study the effects of pollutants on earthworm

\footnotetext{
* Corresponding author. Tel.: +33 4327224 38; fax: +33 432722282 .

E-mail address: capowiez@avignon.inra.fr (Y. Capowiez).
}

burrowing behaviour were based on the use of X-ray tomography (Capowiez et al., 2006) or 2D terraria (Capowiez and Bérard, 2006) which are expensive and have very specific methods resulting in a limited number of observations. Furthermore both methods require either image analysis or complex mathematical analysis to translate the observations into measurements (endpoints). Overall, even if of scientific value, these techniques may prove difficult to justify.

Earthworms burrow in the soil either by ingesting soil particles or by pushing them aside (Lee and Foster, 1991). In addition, soil ingestion is necessary for alimentary reasons. After gut transfer, the soil is egested in a specific feature: the cast. It is deposited either on the soil surface or in the soil itself (Whalen et al., 2004). Cast production (CP) therefore contributes to soil bioturbation, i.e. the disruption and mixing of soils or sediments by organisms that live and/or feed in them and/or simply pass through them. Casts per se play an important ecological role in the soil (Lee and Foster, 1991; Blanchart, 1992; Le Bayon and Binet, 1999) and, equally, they can also be used as a proxy for earthworm activity. This latter approach was recently adopted by Loranger-Mercidis et al. (2008) to study potential interactions between earthworms and woodlice. Subsurface and/or surface cast production was examined in a great number of studies under controlled or natural conditions. Casting was shown to be influenced by biotic factors, such as the earthworm species under consideration (Scheu, 1987; Hindell et al., 1994), species association (Scullion and Ramshaw, 1988), but also 
by abiotic conditions, such as soil bulk density (Le Bayon and Binet, 1999), organic matter type and quantity (Shipitalo et al., 1988; Flegel et al., 1998; Buck et al., 1999), temperature, or water potential (Scheu, 1987; Hindell et al., 1994; Daniel et al., 1996). Overall, the results are difficult to compare directly since the methodologies used to sample earthworm casts were often very different (hand collecting, wet or dry sieving) and the results have been expressed in a variety of ways (number, area covered or weight of casts related to earthworm fresh or dry weight).

There is some limited evidence that pesticides can affect CP. It is well known that the application of some pesticides to golf courses (turf grasses) results in lower surface CP (Baker et al., 1998; Lal et al., 2001). However, we do not know in these cases if earthworms were casting more below ground (to avoid pesticides at the soil surface) or if earthworm abundance simply decreased. In studies of aquatic systems, measurements of the egestion rate of sediments by benthic invertebrates such as oligochaetes (Lumbriculus variegatus) or bivalves (Hydrobia ulvae) have been successfully used in sediment toxicity testing (Leppänen and Kukkonen, 1998; Shipp and Grant, 2006; Penttinen et al., 2008). To our knowledge, the effect of pollutants on earthworm CP has not been studied to date for ecotoxicology purposes. To set the foundations for using $\mathrm{CP}$ measurements in ecotoxicity testing, we initially conducted a series of experiments to investigate the influence of earthworm weight and soil moisture content on $\mathrm{CP}$. We then studied the effectiveness of using $\mathrm{CP}$ as a biomarker for exposure of Lumbricus terrestris earthworms to 6 different pesticides. The aim of the study is to propose a new ecotoxicity test which produces reproducible and relevant results, is relatively easy to conduct and could be considered as a possible candidate for a standardized test in soil risk assessment protocols.

\section{Materials and methods}

\subsection{Soil, earthworms and the sieving protocol}

Soil (23.4\% clay, $57 \%$ silt, $19.6 \%$ sand, $28.3 \mathrm{~g} \mathrm{~kg}^{-1}$ organic matter, $\mathrm{pH}=8.3$, CEC $=8.2 \mathrm{cmol} \mathrm{kg}^{-1}$ ) was collected from an apple orchard abandoned in 1995 and located in Montfavet near Avignon, in south-eastern France. The water holding capacity (WHC) of the soil was $0.247 \mathrm{~g} \mathrm{~g}^{-1}$. Total heavy metal concentrations were measured in the soil $\left(\mathrm{Cu}=30.0, \mathrm{Zn}=76.8, \mathrm{~Pb}=30.0\right.$ and $\left.\mathrm{Cd}=0.290 \mathrm{mg} \mathrm{kg}^{-1}\right)$. Adult and subadult earthworms (L. terrestris) were purchased from a local supplier (fisheries store). They were raised in Canadian farms and are therefore available all year round. The worms were acclimated in the orchard soil for 4 days prior to experiments.

In all experiments, the soil was primarily sieved at $3 \mathrm{~mm}$. Soil moisture was measured and adjusted to the desired value by adding distilled water, mixing the soil and then setting it apart for 2 days in a dark chamber at $12{ }^{\circ} \mathrm{C}$ to reach equilibrium. Before each experiment, the soil was re-sieved and the moisture content was verified. At the beginning of each experiment, earthworms were washed in tap water, blotted dried on filter paper, weighed (without gut voiding) and individually placed for 7 days in $100 \mathrm{~g}$ moist soil in crystal transparent polystyrene round boxes (diameter $=10 \mathrm{~cm}$; height $=3 \mathrm{~cm}$; purchased at Caubère, Yebles, France) and called hereafter Petri dishes. Controls were set up in which no earthworms were added to the soil in the Petri dishes. Earthworms were weighed again (without gut voiding) at the end of the experiment.

In many previous studies (Scheu, 1987; Shipitalo et al., 1988; Buck et al., 1999), casts were collected manually after visual assessment (according to shape and size). For the sake of reproducibility and accuracy, in this study we separated out casts using a set of 4 sieves (diameter $=15 \mathrm{~cm}$ and mesh sizes $=5.6,4,3.15,2.5 \mathrm{~mm}$ ) since earthworm activity may modify soil granulometry leading to an increase in the amount of soil retained in some sieves (casting) and a decrease in others (soil consumption). All soil from each Petri dish, including the soil that adhered to the walls of the dishes which was removed with a knife, was sieved taking care not to break up the casts. The set of sieves was manually shaken for $10 \mathrm{~s}$. The soil retained in each sieve was weighed. The effect of earthworm bioturbation was then examined by determining the changes in the particle size distribution (PSD), i.e. weight of fresh soil in each sieve minus the corresponding weight of soil for the control soil (without earthworm bioturbation).

\subsection{Optimisation of the sieving protocol}

To optimise the protocol, we independently assessed CP dependence on (i) earthworm weight, (ii) soil water content and (iii) drying the soil at the end of the experiment. Most authors (Scheu, 1987; Shipitalo et al., 1988; Curry and Baker, 1998) expressed CP on a weight basis (i.e. in $\mathrm{g}$ of soil per $\mathrm{g}$ of earthworm body mass) so we investigated the relationship between earthworm weight and $\mathrm{CP}$ using 60 Petri dishes. Adults or subadults of $L$. terrestris with a large range of body masses (from 1.13 to $6.38 \mathrm{~g}$ with a mean of 3.69 and a standard deviation of $1.26 \mathrm{~g}$ ) were placed in fifty of them. Ten Petri dishes without earthworms were set up as a control.

Earthworm activity (burrowing and casting) is influenced by water potential and hence soil water content (Kretzschmar, 1991; Daniel et al., 1996). However, soils with high water contents are difficult to sieve because wet soil aggregates tend to combine. We therefore studied the relationship between $\mathrm{CP}$ and water content using 100 Petri dishes and 5 different soil water contents (15, 18, 21, 24 and 27\% expressed on a weight/weight basis) ranging from 60 to $110 \%$ of the WHC. For each soil water content, 20 Petri dishes were fill with moist soil, 10 without earthworms (control) and 10 containing one $L$. terrestris. Because earthworm weights were variable and ranged from 2.47 to $5.62 \mathrm{~g}$, a blocking procedure was used so that mean earthworm weight was similar in each treatment (McIndoe et al., 1998). This blocking procedure was used for the following experiments.

We hypothesised that waiting for the soil to dry at the end of the experiment may facilitate soil sieving. This in turn could influence the results of $\mathrm{CP}$ as a possible ecotoxicity test. To investigate this idea, a test was carried out using 160 Petri dishes and a carbamate insecticide (Lannate ${ }^{\odot}$, DuPont) the active ingredient of which is methomyl. Moist soil was prepared at initially $19.2 \%$ water content. Soil was contaminated by manually spraying each $\mathrm{kg}$ of soil with $40 \mathrm{ml}$ of a solution containing increasing concentrations of methomyl. Control soil was sprayed with the same quantity of water. The spiking procedure, which generated good levels of pollution homogeneity, was described in detail and tested by Capowiez et al. (2005). The methomyl concentrations were chosen based on the usual application rate and calculation of the PEC (Predicted Environmental Concentration i.e. a single application of $750 \mathrm{~g}$ a.i. ha ${ }^{-1}$, with a homogeneous distribution in the first $5 \mathrm{~cm}$ of soil, no crop interception and a soil density of $\left.1.5 \mathrm{~kg} \mathrm{l}^{-1}\right)$. This normal application rate $\left(2.025 \mathrm{mg}\right.$ a.i. $\mathrm{kg}^{-1}$ of wet soil) is termed ' $1 \times$ ' and we then used the following concentrations: ' $10 \times$ ', ' $0.1 \times$ ' accordingly. For each pesticide concentration, 40 Petri dishes were filled with moist soil and one L. terrestris (range weight was 1.69-5.97) was added in half of them. The final soil water content was $24 \%$. After 7 days of exposure at $12{ }^{\circ} \mathrm{C}$ in a dark chamber, earthworms were weighed. The soil in half of the Petri dishes was sieved immediately. The other half was sieved after the Petri dishes were dried for 4 days at laboratory temperature (about $25^{\circ} \mathrm{C}$ ). The soil water content of 3 Petri dishes was measured in each treatment. Because casts were dried, this time CP was expressed in $\%$ of weight of the available soil $\mathrm{g}^{-1}$ fresh body mass day ${ }^{-1}$ to enable direct comparisons between fresh and dried soil (each worm was in $100 \mathrm{~g}$ of moist soil).

\subsection{Effect of 6 pesticides on cast production}

The sensitivity of $\mathrm{CP}$ as a behavioural biomarker was tested using 6 pesticides (Table 1). Four of these were long-standing and broad-spectrum insecticides belonging to the carbamate and organophosphorous families, which are currently still used in apple orchards in Provence (South-East of France) due to the increasing resistance of codling moths to other pesticides (Sauphanor et al., 2000). The fifth (ethyl-parathion) was banned by the EEC in 2001 but was used in the present study as a model pesticide so that comparisons with previously published data (OlveraVelona et al., 2008) were possible. The last (imidacloprid) is a relatively new insecticide belonging to the family of neonicotinoids, which is currently used in peach orchards against aphids. This pesticide was previously shown to cause behavioural effects on earthworms even at low concentrations close to the PEC (Capowiez and Bérard, 2006). It was then used in the present study at lower concentrations than these other pesticides (Table 1). Four of these pesticides were classified as very toxic or extremely toxic to earthworms by Edwards and Bohlen (1996) whereas they found insufficient evidence to categorize azinphos-methyl. Imidacloprid was initially categorized as moderately toxic to earthworms by Elbert et al. (1990). The soil spiking procedure was as explained previously except that only 20 Petri dishes were filled with most soil for each pesticide concentration, 10 contained an earthworm and 10 did not. The final soil water content was $24 \%$. The adults or subadults of $L$. terrestris used had an average weight of $4.01 \mathrm{~g}$ (the range of weight was $1.57-6.09 \mathrm{~g})$. After 7 days of exposure in a dark chamber at $12{ }^{\circ} \mathrm{C}$, the earthworms were re-weighed and the soil was sieved immediately by the same operator (wearing a mask when handling polluted).

\subsection{Statistical analyses}

Data were tested for normal distribution and homogeneity of variance and then were log-transformed before the ANOVA or regression analysis as necessary. The relationships between $\mathrm{CP}$ (in $\mathrm{g}$ of fresh soil day ${ }^{-1}$ ) and earthworm fresh weight were assessed using linear regression. To study the effects of the soil water content on $\mathrm{CP}$ (in $\mathrm{g} \mathrm{g}^{-1} \mathrm{day}^{-1}$ ) we performed a one-way ANOVA. The effect of drying the soil at the end of the experiment was assessed with a two-way ANOVA with soil drying and pesticide dose as factors. To study the effects of the 6 pesticides on CP or weight loss, 
Table 1

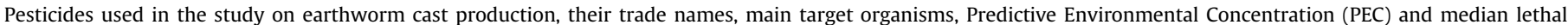
concentrations $\left(\mathrm{LC}_{50}\right.$ ) for the effect on earthworm survival taken from the literature.

\begin{tabular}{|c|c|c|c|c|c|c|c|}
\hline $\begin{array}{l}\text { Active } \\
\text { ingredient }\end{array}$ & $\begin{array}{l}\text { Commercial } \\
\text { name }\end{array}$ & Targets & $\begin{array}{l}\text { Application } \\
\text { rate }\left(\mathrm{g} \mathrm{ha}^{-1}\right)\end{array}$ & $\begin{array}{l}\text { PEC }=\text { Soil concentration } \\
\left(\mathrm{mg} \text { a.i. } \mathrm{kg}^{-1} \text { dry soil }\right)^{\mathrm{a}}\end{array}$ & $\begin{array}{l}\mathrm{LD}_{50} \\
\text { (mg kg } \\
\text { (1) dry soil) }\end{array}$ & $\begin{array}{l}\text { Duration of the } \\
\text { toxicity test }\end{array}$ & Species used \\
\hline Methomyl & Lannate & Codling moth Aphids & 750 & 2.025 & $90^{c}$ & 14 & E. fetida \\
\hline Chlorpyrifos-ethyl & Pyrinex ME & Codling moth & 500 & 1.35 & $129^{\mathrm{d}}$ & 14 & E. fetida \\
\hline Carbaryl & Sevin L85 & Codling moth & 850 & 2.295 & $9^{e}$ & 7 & Pheretima \\
\hline Ethyl-parathion ${ }^{\mathrm{b}}$ & Oleobladan & Codling moth & 250 & 0.675 & $32^{f}$ & 14 & A. caliginosa \\
\hline Azinphos-methyl & Gusathion XL & Codling moth Aphids & 437.5 & 1.18 & $158^{g}$ & 14 & E. fetida \\
\hline Imidacloprid & Confidor & Aphids & 70 & 0.189 & $10.7^{\mathrm{d}}$ & 14 & E. fetida \\
\hline
\end{tabular}

a Single application with a homogeneous distribution in the first $5 \mathrm{~cm}$ of soil with a density of $1.5 \mathrm{~kg} \mathrm{l^{-1 }}$ and no crop interception.

b Forbidden since 2001 in EEC.

c Armstrong et al. (1991).

d Agritox database (www.dive.afssa.fr/agritox/index.php).

e Mostert et al., 2002.

f Olvera-Velona et al. (2008).

g Heimbach (1986).

we performed 6 independent one-way ANOVA. All tests were carried out using R-software ( $R, 2005)$. In every case the significance threshold was set to $5 \%$.

\section{Results}

\subsection{Optimisation of the sieving protocol}

In all experiments, positive values of PSD were consistently found for only the largest sieve size $(5.6 \mathrm{~mm})$. Because the values of PSD obtained for the second sieve $(4 \mathrm{~mm})$ were either very low or negative it was then decided to compute the CP using only the values obtained with the largest sieve size.

A positive and linear correlation was observed between the raw $\mathrm{CP}$ (expressed in $\mathrm{g}$ of soil day $\left.{ }^{-1}\right)$ and earthworm weight $\left(R^{2}=0.623\right.$; $p<0.01 ; \mathrm{CP}=0.674 \mathrm{EW}+0.068$ with $\mathrm{CP}$, (cast production in $\mathrm{d} \mathrm{day}^{-1}$ of soil) and EW, (earthworm fresh weight in g)). Thus, in the following experiments, the $\mathrm{CP}$ was expressed as cast fresh weight per earthworm fresh body mass per day $\left(\mathrm{g} \mathrm{g}^{-1} \mathrm{day}^{-1}\right)$.

The soil water content (up to $24 \%$ ) had a significant effect on CP which increased from 0.034 at $15 \%$ to $0.752 \mathrm{~g} \mathrm{~g}^{-1} \mathrm{day}^{-1}$ at $24 \%$ soil water content (Table 2 ). For the highest soil water content (27\%), we did not observe a significantly lower CP value than for $24 \%$ but the variability was much higher. Furthermore, at 27\% soil water content, very large amounts of soil were found in the $5.6 \mathrm{~mm}$ sieve from the control without earthworms (Table 2) even if the soil was initially sieved at $3 \mathrm{~mm}$.

After 4 days at ambient temperature, the mean soil water content decreased from 20.7 to $1.7 \%$ with no significant difference between the treatments, i.e. methomyl concentration (data not shown). This time, CP was expressed as the \% of soil weight available $\mathrm{g}^{-1}$ of body mass day $^{-1}$ so that the amount of dry and fresh casts can be compared. $\mathrm{CP}$ was significantly influenced by the pesticide concentration $(p<0.01)$ but not by the drying procedure $(p=0.192)$. The interaction between these two factors was not significant. The presence of methomyl led to significant decreases in CP of 45 and $65 \%$ at $1 \times$ and $10 \times$, respectively, compared to the control (Fig. 1 ).

\subsection{Effects of the 6 pesticides on $C P$ and body mass}

Following finding from the optimisation protocol, soil water content was set at $24 \%$ and sieving was carried out immediately after the 7th day of exposure. Azinphos-methyl was the only pesticide which did not have a significant effect on CP (Fig. 2). Chlorpyrifos-ethyl and ethyl-parathion had a significant effect on $\mathrm{CP}$ but without a clear concentration-effect relationship $(10 \times$ was not significantly different from $0.1 \times$ ). In addition, the decreases in CP for $10 \times$ were limited to 38 and $35 \%$ for chlorpyrifos-ethyl and ethyl-parathion, respectively (Fig. 2). The other three pesticides showed significant effects on $\mathrm{CP}$ with a concentration-effect response. The decreases in $\mathrm{CP}$ for the highest pesticide concentration were 67, 54 and 61\% for methomyl, carbaryl and imidacloprid, respectively. Due to the limited number of concentrations tested it was not possible to compute an $\mathrm{EC}_{50}$. For chlorpyrifos-ethyl and carbaryl, significant decreases in $\mathrm{CP}$ were observed for the $0.1 \times$ treatment.

Body mass changes of $L$. terrestris after the 7 days of exposure showed significant differences even for the lowest concentrations $(0.1 \times)$ tested except for imidacloprid (Table 3$)$. Whereas earthworms in the control soil gained weight (11\%), a decrease in body mass was observed at $1 \times$ for methomyl, carbaryl and ethyl-parathion and for all pesticides at $10 \times$. Overall, the body mass decreases were limited and smaller than $20 \%$ (except for methomyl).

\section{Discussion}

\subsection{Optimisation of the sieving test}

In the present study we focused on some aspects of the sieving protocol in order to determine if (i) earthworms of various body mass can be used, and, whether (ii) the soil water content during the experiment or during the sieving has an influence on CP itself and on our ability to accurately measure $\mathrm{CP}$.

As expected, we observed a significant and linear relationship between initial earthworm body mass and CP (expressed in $g$ of soil). The same result was found by Scheu (1987) for Aporrectodea caliginosa and most authors express CP in $\mathrm{g}$ of dry or wet soil $\mathrm{g}^{-1}$ of body mass day ${ }^{-1}$. Occasionally, very small earthworms (juveniles) were reported to produce a greater weight of casts than adults or subadults: Bolton and Phillipson (1976) observed this for Aporrectodea rosea but only at $14.8^{\circ} \mathrm{C}$ the highest of the 3 temperatures tested and Daniel et al. (1996) reported a similar finding for

Table 2

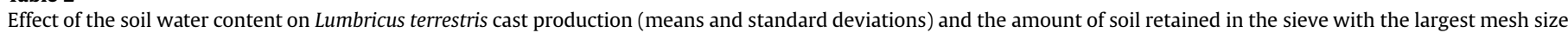
$(5.6 \mathrm{~mm})$ from control Petri dishes without earthworms $(n=10)$. Values labeled with the same letter are not significantly different at the $5 \%$ level.

\begin{tabular}{|c|c|c|c|c|c|}
\hline Soil water content $\left(\mathrm{g} \mathrm{g}^{-1}\right)$ & $15 \%$ & $18 \%$ & $21 \%$ & $24 \%$ & $27 \%$ \\
\hline Cast production (fresh $\mathrm{g} \mathrm{g}^{-1}$ fresh body mass day ${ }^{-1}$ ) & $0.034^{\mathrm{C}}(0.037)$ & $0.125^{\mathrm{c}}(0.075)$ & $0.357^{\mathrm{b}}(0.101)$ & $0.752^{\mathrm{a}}(0.148)$ & $0.712^{\mathrm{a}}(0.275)$ \\
\hline Soil in the sieve with the largest mesh size from controls without earthworms ( $g$ ) & $0.00(0.00)$ & $0.03(0.01)$ & $0.06(0.01)$ & $0.10(0.01)$ & $14.22(0.34)$ \\
\hline
\end{tabular}




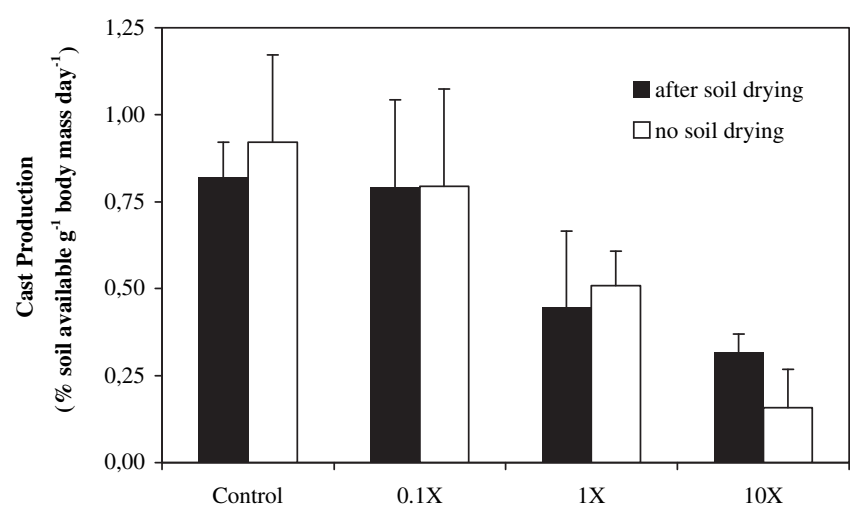

Fig. 1. Effect of different concentrations in methomyl $(1 \times=$ normal application rate) on Lumbricus terrestris cast production (means and standard deviations) expressed in \% of soil available (each earthworm was given $100 \mathrm{~g}$ of moist soil) $\mathrm{g}^{-1}$ of fresh body mass day $^{-1}$. Cast production was estimated either immediately at the end of the 7 days exposure period (no soil drying) or 4 days later (after soil had been allowed to dry).

Aporrectodea nocturna. In both cases, only surface casts were included in the study. Furthermore, in the latter study, CP was expressed in $\mathrm{g}$ dry cast $\mathrm{g}^{-1}$ of earthworm dry weight. Indeed, the lack of standardized units for expressing $\mathrm{CP}$ often makes direct comparisons between results from different studies difficult or impossible. In this study, because we did not dry the casts or only focus on surface casts, the mean values obtained for $L$. terrestris CP $\left(0.714 \mathrm{~g}\right.$ of fresh soil $\mathrm{g}^{-1}$ body mass day $\left.{ }^{-1}\right)$ were higher than the range of values reported by previous authors: $0.10-0.18$ for Shipitalo et al. (1988), 0.25 for Hartenstein and Amico (1983) and 0.25$0.43 \mathrm{~g} \mathrm{~g}^{-1} \mathrm{day}^{-1}$ for Buck et al. (1999).

As observed by many authors (Kretzschmar, 1991; Hindell et al., 1994; Daniel et al., 1996), earthworm activity and therefore CP increased with the soil water content. However, for the highest soil water content we tested, non-biogenic soil aggregates tended to combine and sieving became difficult leading to higher values than expected for the controls (without earthworms) and a high variability in the $\mathrm{CP}$ measurements. It therefore appeared that, for the soil used in this study, the optimal soil water content to accurately estimate CP is $24 \%$. In addition, drying the soil at the end of the experiment had no influence on $\mathrm{CP}$ estimations, meaning that soil can be sieved immediately at the end of the experiment.

The protocol we used to estimate $\mathrm{CP}$ is relatively simple and not time-consuming (if only one sieve adapted to the earthworm species is used). Hand shaking can be a source of variability so in this study, all tests were carried out by the same person. Diaz-Zorita et al. (2007) showed that sieving duration has no effect when using sieves with a mesh size larger than $4 \mathrm{~mm}$. In future experiments, however, $\mathrm{CP}$ estimations could be standardized by using automatic sieve shakers.
Table 3

Body mass changes (means and standard deviations) of Lumbricus terrestris due to exposure to 6 different pesticides for 7 days expressed as a percentage of initial body mass set at $100 \%$. Values in bold are significantly different from the control value $(n=10)$. Values labeled with the same letters are not significantly different at the $5 \%$ level (each pesticide was tested separately).

\begin{tabular}{lllll}
\hline & Control & $0.1 \times$ & $1 \times$ & $10 \times$ \\
\hline Methomyl & $111.0^{\mathbf{a}}(8.2)$ & $\mathbf{1 0 0 . 5}^{\mathbf{b}}(\mathbf{1 5 . 6})$ & $\mathbf{9 3 . 4}^{\mathbf{b}}(\mathbf{7 . 4})$ & $\mathbf{7 6 . 6}^{\mathbf{c}}(\mathbf{9 . 4 )}$ \\
Chlorpyrifos-ethyl & & $\mathbf{1 0 1 . 1}^{\mathbf{b}}(\mathbf{7 . 0})$ & $\mathbf{1 0 0}^{\mathbf{b}}(\mathbf{5 . 5})$ & $\mathbf{9 7 . 6}^{\mathbf{b}}(\mathbf{1 2 . 2})$ \\
Carbaryl & & $\mathbf{9 9 . 7}^{\mathbf{b}}(\mathbf{9 . 2})$ & $\mathbf{8 9 . 0}^{\mathbf{c}}(\mathbf{1 0 . 0})$ & $\mathbf{8 1 . 9}^{\mathbf{c}}(\mathbf{1 2 . 2})$ \\
Ethyl-parathion & & $\mathbf{1 0 3 . 3}^{\mathbf{b}}(\mathbf{9 . 0})$ & $\mathbf{9 5 . 4}^{\mathbf{c}}(\mathbf{5 . 0})$ & $\mathbf{8 5 . 7}^{\mathbf{d}}(\mathbf{4 . 3 )}$ \\
Imidacloprid & & $111.8^{\mathbf{a}}(9.4)$ & $\mathbf{1 0 3 . 6}^{\mathbf{b}}(\mathbf{1 2 . 1})$ & $\mathbf{9 3 . 9}^{\mathbf{c}}(\mathbf{8 . 3})$ \\
Azinphos-methyl & & $\mathbf{9 5 . 7}^{\mathbf{b}}(\mathbf{7 . 6})$ & $\mathbf{1 0 1 . 1}^{\mathbf{b}}(\mathbf{8 . 2})$ & $\mathbf{8 1 . 4}^{\mathbf{c}}(\mathbf{1 1 . 1})$ \\
\hline
\end{tabular}

\subsection{Cast production is a promising biomarker}

A decrease in $\mathrm{CP}$ in the presence of pesticides appears to be a sensitive marker of toxic effects. Different kinds of responses, from no effect to a clear concentration effect, were observed. These different responses are in relative agreement with previously determined characteristics of the toxicity of the tested pesticides to earthworms (Table 1 ). Although the $\mathrm{LD}_{50}$ for each of the pesticides used were computed on different earthworm species and under different time frames, it is still relevant to divide the $\mathrm{LD}_{50}$ by the $\mathrm{PEC}$, to give a toxicity ranking as is frequently done in ecological risk assessments. Three different groups of values were obtained: (i) below 10 for carbaryl; (ii) between 40 and 60 for methomyl, methyl-parathion and imidacloprid; (iii) close to 100 for chlorpyrifos-methyl and azinphos-methyl (the higher this value is, the lower is predicted toxicity). Interestingly, the effects on $\mathrm{CP}$ were approximately the same as this ranking: azinphos showed no toxic effects, ethyl-parathion and chlorpyrifos-ethyl led to a significant decrease in $\mathrm{CP}$ without a clear concentration-effect response and finally there was a clear concentration-effect response with methomyl, imidacloprid and carbaryl. CP appears to be generally highly sensitive to pesticides with the $1 \times$ concentration of 5 of the pesticides leading to a significant decrease in $\mathrm{CP}$ and with 2 of the pesticides showing effects at even the $0.1 \times$ concentration. Importantly, this indicates that field (or even 10 times lower) concentrations of currently used pesticides may have a negative influence on earthworm behaviour, and thus, also on soil functioning.

Earthworms exposed to the pesticides tested showed significant weight losses even at low concentrations (except for imidacloprid at $0.1 \times$ ). This was unexpected because a previous study using endogeic earthworms exposed to ethyl-parathion, reported that this marker was less sensitive and more variable than behavioural endpoints related to burrowing behaviour (Olvera-Velona et al., 2008). Weight loss was significant but the range of variation was rather limited (rarely more than 20\%) in this experiment. Furthermore, if the pesticides are ranked using this marker it does not

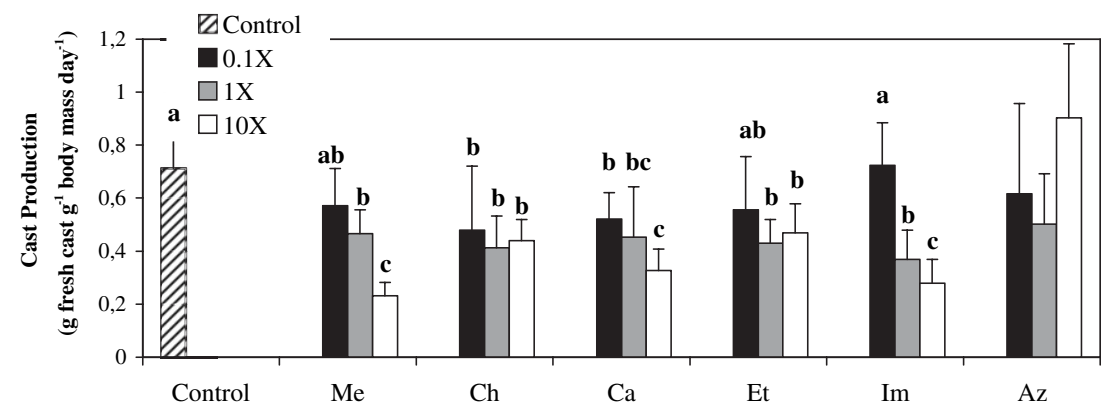

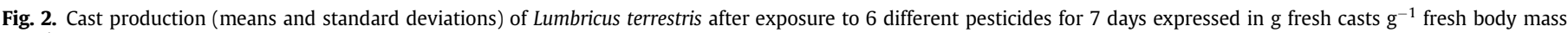

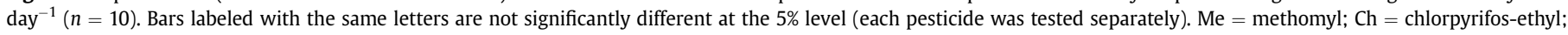
$\mathrm{Ca}=$ carbaryl; $\mathrm{Et}=$ ethyl-parathion; $\mathrm{Im}=$ imidacloprid $\mathrm{Az}=$ azinphos-methyl 
correlate with the toxicity given by the $\mathrm{LD}_{50}$ and PEC data (for example azinphos-methyl appeared to be as toxic as methomyl and imidacloprid at the $10 \times$ concentration).

Regarding published sublethal effects on earthworms, no data were found for methomyl. Springett and Gray (1992) reported that azinphos methyl had negative effects on $A$. caliginosa growth but when applied at a normal application rate every week for 100 days. For chlorpyrifos-ethyl, studies reported no sublethal effects (Mostert et al., 2000; Booth and O'Halloran, 2001). For carbaryl, imidacloprid and ethyl-parathion, significant influences on sublethal, including behavioural endpoints, were observed for concentrations close to or below the PEC reported in Table 1 (Gupta and Saxena, 2003; Capowiez et al., 2005; Capowiez and Bérard, 2006; OlveraVelona et al., 2008; Gomez-Eyles et al., 2009). Our findings on CP are in agreement with these previous studies. Interestingly, in their recent study, Gomez-Eyles et al. (2009) measured the feeding rate of $E$. fetida after exposure to imidacloprid (estimated by the quantity of ingested manure). They showed that this endpoint was very sensitive and observed significant reductions in manure ingestion at imidacloprid concentrations as low as $1.91 \mathrm{mg} \mathrm{kg}^{-1}$.

In the present study, most of the casts were sampled using the sieve with a mesh size of $5.6 \mathrm{~mm}$. For all the other sieves, values of PSD were generally negative or very low. This $5.65 \mathrm{~mm}$ value is rather high compared to the $2 \mathrm{~mm}$ threshold size generally used to isolate earthworm casts (Blanchart, 1992). However it should be noted that only adults or subadults, hence large $L$. terrestris (with a mean weight of $4.01 \mathrm{~g}$ ), were used in this study. It is known that other soil organisms such as fungi and other micro-organisms can also influence soil aggregation (Tisdall and Oades, 1982; Elmholt et al., 2008). In our experimental set up these organisms are also exposed to the pesticides and their role in soil aggregation may or may not have been modified (Helfrich et al., 2008). Theoretically, this could have influenced $\mathrm{CP}$. However, because we measured CP using only the larger mesh size and an earthworm-free control consisting of soil alone was used for each pesticide concentration, we suggest that the influence of these organisms in our estimation of $\mathrm{CP}$ was negligible.

Due to their important roles in soil ecosystems, earthworms are terrestrial model organisms requiring testing. Currently several standardized tests using earthworms are available. The first tests examined earthworm mortality (on paper filter or in artificial or natural soils) in order to establish the $\mathrm{LD}_{50}$ (ISO, 1993). Then other tests were developed based on sublethal endpoints such as reproduction (ISO, 1998) or behaviour (avoidance; ISO, 2008). E. fetida is the model organism in all of these tests and, for example, the reproduction test is only possible with epigeic worms due to their short reproduction cycle. Another drawback is that this reproduction test takes 28 days. The avoidance test is a behavioural test with several advantages (simple, quick and cheap) but one drawback: this is not a measure of toxicity but rather a measure of repellence (Capowiez and Bérard, 2006), and thus is termed 'measure of habitat modification'. As there is not always a direct relationship between avoidance and toxicity, an improvement of this test was recently proposed by Sanchez-Hernandez (2006). Our behavioural test, based on estimations of $\mathrm{CP}$, is straightforward, quick, does not require specific equipment and mitigates most of the drawbacks listed above for other behavioural standardized tests. Of special importance, it is adapted to earthworm species with higher ecological relevance (Lowe and Butt, 2005) and takes only 7 days. Furthermore, the results are easy to interpret: $\mathrm{CP}$ simply represents the quantity of soil the earthworms egested and may be correlated to the quantity ingested (feeding behaviour). However, a disadvantage of this test worth mentioning is that when a decrease in $\mathrm{CP}$ was observed, our results do not clearly determine whether earthworms ingested less soil because their health was affected or because the polluted soil acted as a repellent. Another drawback of $\mathrm{CP}$ as a biomarker is that it appears to be a difficult approach for use with E. fetida since our first attempts to estimate CP for epigeic earthworms (E. fetida or Dendrobaena veneta) failed even using sieves with smaller mesh sizes.

In conclusion, $\mathrm{CP}$ appears to be a relevant (i.e. ecologically meaningful) and promising biomarker for ecotoxicity tests. Some aspects should be carefully considered for this marker to be widely used and accepted. First of all, preliminary tests need to be carried out to adapt (i) mesh size and test duration to the earthworm species under investigation and (ii) soil water content to soil texture. The key parameters are the soil moisture content and the initial soil particle size distribution. These parameters are not easy to control for large quantities of soil, so we recommend that in order to minimize variability, the soil to be incubated with and without earthworms should be prepared at the same time for each pesticide or pollutant concentration.

\section{Acknowledgements}

Perceval Depresles, Pierrick and Odile Mascle are thanked for their technical help.

\section{References}

Armstrong, K., Caley, C.Y., Hall, B.E., Knight, B., 1991. Lannate 20L: Determination of Acute Toxicity (LC50) in Earthworms. Inveresk Research International Ltd, Tranent, Scotland (Unpublished report No. 8546).

Baker, S.W., Binns, D.J., Kirby, E.C., 1998. Reduction in rates of earthworm casting on turf areas using carbendazim, carbaryl and gamma-HCH + thiophanate-methyl. Journal of the Sports Turf Research Institute 74, 25-39.

Blanchart, E., 1992. Restoration by earthworms (Megascoledidae) of the macroaggregate structure of a destructed savanna soil under field conditions. Soil Biology and Biochemistry 24, 1587-1594.

Bolton, P.J., Phillipson, J., 1976. Burrowing, feeding, egestion and energy budgets of Allolobophora rosea (Savigny) (Lumbricidae). Oecologia 23, 225-245.

Booth, L.H., O'Halloran, K., 2001. A comparison of biomarker response in the earthworm Aporrectodea caliginosa to the organophosphorus insecticides diazinon and chlorpyrifos. Environmental Toxicology and Chemistry 20, 2494-2502.

Buck, C., Langmaack, M., Schrader, M., 1999. Nutrient content of earthworm casts influences by different mulch types. European Journal of Soil Biology 35, 23-30.

Capowiez, Y., Rault, M., Mazzia, C., Belzunces, L., 2003. Earthworm behaviour as a biomarker: a study case using imidacloprid. Pedobiologia 47, 542-547.

Capowiez, Y., Rault, M., Costagliola, G., Mazzia, C., 2005. Lethal and sublethal effects of imidacloprid on two earthworm species (Aporrectodea nocturna and Allolobophora icterica). Biology and Fertility of Soils 41, 135-143.

Capowiez, Y., Bérard, A., 2006. Assessment of the effects of imidacloprid on the behavior of two earthworm species (Aporrectodea nocturna and Allolobophora icterica) using 2D terraria. Ecotoxicology and Environmental Safety 64, 198-206.

Capowiez, Y., Bastardie, F., Costagliola, G., 2006. Sublethal effects of imidacloprid on the burrowing behaviour of two earthworm species: modifications of the 3D burrow systems in artificial soil cores and consequences on gas diffusion in soil. Soil Biology and Biochemistry 38, 285-293.

Curry, J.P., Baker, G.H., 1998. Cast production and soil turnover by earthworms in soil cores from South Australian pastures. Pedobiologia 42, 283-287.

Daniel, O., Kohli, L., Schuler, B., Zeyer, J., 1996. Surface cast production by the earthworm Aporrectodea nocturna in a pre-alpine meadow in Switzerland. Biology and Fertility of Soils 22, 171-178.

Diaz-Zorita, M., Grove, J.H., Perfect, E., 2007. Sieving duration and sieve loading impacts on dry soil fragment size distributions. Soil and Tillage Research 94, 15-20.

Doving, K.B., 1991. Assessment of animal behaviour as a method to indicate environmental toxicity. Comparative Biochemistry and Physiology Part C 100, 247-252.

Edwards, C.A., Bohlen, P.J., 1996. Biology and Ecology of Earthworms. Chapman and Hall, London, UK.

Eijsackers, H., van Gestel, C.A.M., de Jonge, S., Muijs, B., Slijkerman, D., 2001. Polycyclic aromatic hydrocarbon-polluted dredged peat sediments and earthworms: a mutual interference. Ecotoxicology 10, 35-50.

Elbert, A., Overbeck, H., Iwaya, K., Tsuboi, S., 1990. Imidacloprid, a novel systemic nitromethylene analogue for crop protection. Proceedings, 1990 Brighton Crop Protection Conference Pests and Diseases 1, 21-28.

Elmholt, S., Schjonning, P., Munkholm, L.J., Debosz, K., 2008. Soil management effects on aggregates stability and biological binding. Geoderma 144 455-467.

Flegel, M., Schrader, M., Zhang, H., 1998. Influence of food quality on the physical and chemical properties of detritivorous earthworm cats. Applied Soil Ecology 9, 263-269. 
Gomez-Eyles, J.L., Svendsen, C., Lister, L., Martin, H., Hodson, M., Spurgeon, J.D., 2009. Measuring and modelling mixture toxicity of imidacloprid and thiacloprid on Caenorhabditis elegans and Eisenia fetida. Ecotoxicology and Environmental Safety 72, 71-79.

Görres, J.H., Savin, M.C., Amador, J.A., 2001. Soil micropore structure and carbon mineralization in burrows and casts of an anecic earthworm (Lumbricus terrestris). Soil Biology and Biochemistry 33, 1881-1887.

Gupta, S.K., Saxena, P.M., 2003. Carbaryl-induced behavioural and reproductive abnormalities in the earthworm Metaphire posthuma: a sensitive model. Alternatives to Laboratory Animals 31, 587-593.

Hartenstein, R., Amico, L., 1983. Production and carrying capacity for the earthworm Lumbricus terrestris in culture. Soil Biology and Biochemistry 15, 51-54.

Heimbach, F., 1986. Acute Toxicity of Azinphos-methyl to Earthworms. Bayer AG Agricultural Centre, Leverkusen. Report N HBF/Rg 58 (unpublished).

Helfrich, M., Ludwig, B., Potthoff, M., Flessa, M., 2008. Effect of liter quality and soil fungi on macroaggregate dynamics and associated partitioning of liter carbon and nitrogen. Soil Biology and Biochemistry 40, 1823-1835.

Hindell, R.P., McKenzie, B.M., Tisdall, J.M., Silvapulle, M.J., 1994. Relationships between casts of geophagous earthworms (Lumbricidae, Oligochaeta) and matric potential. Biology and Fertility of Soils 18, 119-126.

ISO 11268-1, 1993. Soil Quality - Effects of Pollutants on Earthworms (Eisenia fetida) - Part 1: Determination of Acute Toxicity Using Artificial Soil Substrate. ISO (International Organization for Standardization), Geneva, Switzerland.

ISO 11268-2, 1998. Soil Quality - Effects of Pollutants on Earthworms (Eisenia fetida) - Part 2: Determination of Effects on Reproduction. ISO (International Organization for Standardization), Geneva, Switzerland.

ISO 17512-1, 2008. Soil Quality - Avoidance Test for Determining the Quality of Soils and Effects of Chemicals on Behaviour - Part 1: Test with Earthworms (Eisenia fetida and Eisenia andrei). ISO (International Organization for Standardization), Geneva, Switzerland.

Jones, C.G., Lawton, J.H., Shachak, M., 1994. Organisms as ecosystem engineers. Oikos 69, 373-386

Kretzschmar, A., 1991. Burrowing activity of the earthworm Apporectodea longa limited by soil compaction and water potential. Biology and Fertility of Soils 11, 48-51.

Lal, O.P., Palta, R.K., Srivastava, Y.N.S., 2001. Impact of imidacloprid and carbofuran on earthworm casting in Okra field. Annual Plant Protection Service 9, 137-138.

Le Bayon, R.C., Binet, F., 1999. Space-time dynamics in situ of earthworm casts under temperate cultivated soils. Soil Biology and Biochemistry 31, 85-93.

Lee, K.E., Foster, R.C., 1991. Soil fauna and soil structure. Australian Journal of Soil Science 29, 745-775.

Leppänen, M.T., Kukkonen, J.V.K., 1998. Relationships between reproduction, sediment type, and feeding activity of Lumbriculus varigatus (Müller): implications for sediment toxicity testing. Environmental Toxicology and Chemistry 17, 2196-2202.

Little, E.E., 1990. Behavioral toxicology: stimulating challenges for a growing discipline. Environmental Toxicology and Chemistry 9, 1-2.

Loranger-Mercidis, G., Laossi, K.-R., Bernhard-Reversat, F., 2008. Soil aggregation in a laboratory experiment: interactions between earthworms, woodlice and litter palatability. Pedobiologia 51, 439-443.
Lowe, C.N., Butt, K.R., 2005. Culture techniques for soil dwelling earthworms: a review. Pedobiologia 49, 401-413.

McCoy, E.L., Boast, C.W., Stehouver, R.C., Kladivko, E.J., 1994. Macropore hydraulics: taking a sledgehammer to classical theory. In: Lal, R., Stewart, B.A. (Eds.), Soil Processes and Water Quality. Lewis Publishers, Boca Raton, pp. 303-348.

McIndoe, E.C., Bembridge, J.D., Martin, P., 1998. Improving the accuracy and precision of earthworm laboratory experiments though the use of pretreatment measurements. In: Sheppard, S.C., Bembridge, J.D., Holmstrup, M., Posthuma, L. (Eds.), Advances in Earthworm Ecotoxicology. SETAC, Pensacola, pp. 27-34

Mostert, M.A., Schoeman, A.S., van der Merwe, M., 2000. The toxicity of five insecticides to earthworms of the Pheretima group, using an artificial soil test. Pest Management Science 56, 1093-1097.

Mostert, M.A., Schoeman, A.S., Van der Merwe, M., 2002. The relative toxicity of insecticides to earthworms of the Pheretima group (Oligochaeta). Pest Management Science 58, 446-450.

Olvera-Velona, A., Capowiez, Y., Mascle, O., Ortiz-Hernandez, L., Benoit, P., 2008 Assessment of the toxicity of ethyl-parathion to earthworms (Aporrectodea caliginosa) using behavioural, physiological and biochemical markers. Applied Soil Ecology 40, 476-483.

Penttinen, O.-P., Kilpi-Koski, J. Jokela, M., Toivanen, K., Väisänen, A., 2008. Importance of dose metrics for lethal and sublethal sediment metal toxicity in the oligochaete worm Lumbriculus variegatus. Journal of Soils and Sediments 8, 59-66.

R, 2005. The R Foundation for Statistical Computing Version 2.1.1 (2005-06-20), ISBN 3-900051-07-027.

Sanchez-Hernandez, J.C., 2006. Earthworm biomarkers in ecological risk assessment. Reviews of Environmental Contamination and Toxicology 188, 85-126.

Sauphanor, B., Brosse, V., Bouvier, J.-C., Speich, P., Micou, A., Martinet, C., 2000. Monitoring resistance to diflubenzuron and deltamethrin in French codling moth populations (Cydia pomonella). Pest Management Science 56, 1-9.

Scherrer, E., 1992. Behavioural responses as indicator of environmental alterations: approaches, results, developments. Journal of Applied Ichtyology 8, 122-131.

Scheu, S., 1987. The role of substrate feeding earthworms (Lumbricidae) for bioturbation in a beechwood soil. Oecologia 72, 192-196.

Scullion, J., Ramshaw, G.A., 1988. Factors affecting surface casting behaviour in several species of earthworm. Biology and Fertility of Soils 7, 39-45.

Shipitalo, M.J., Protz, R., Tomlin, A.D., 1988. Effect of diet on the feeding and casting activity of Lumbricus terrestris and L. rubellus in laboratory culture. Soil Biology and Biochemistry 20,233-237.

Shipp, E., Grant, A., 2006. Hydrobia ulvae feeding rates: a novel way to assess sediment toxicity. Environmental Toxicology and Chemistry 25, 3246-3252.

Springett, J.A., Gray, R.A.J., 1992. Effect of repeated low doses of biocides on the earthworm Apporectodea caliginosa in laboratory cultures. Soil Biology and Biochemistry 24, 1739-1744.

Tisdall, J.M., Oades, J.M., 1982. Organic matter and water-stable aggregates in soils. Journal of Soil Science 33, 141-163.

Whalen, J.K., Sampredo, L., Waheed, T., 2004. Quantifying surface and subsurface cast production by earthworms under controlled laboratory conditions. Biology and Fertility of Soils 39, 287-291. 